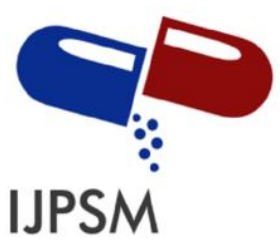

Birla Hariom et al, Int. Journal of Pharmaceutical Sciences and Medicine (IJPSM),

Vol.6 Issue. 1, January- 2021, pg. 40-50

ISSN: 2519-9889

Impact Factor: 3.426

\title{
Simultaneous Estimation of Simvastatin and Ezitimibe by UV Spectroscopy
}

\author{
Birla Hariom*; Dubey Archana \\ Dept. of Pharmaceutical Chemistry, Swami Vivekanand College of Pharmacy, Indore (M.P) India \\ DOI: 10.47760/ijpsm.2021.v06i01.004
}

\begin{abstract}
Simvastatin (SMV) and Ezitimibe (EZT) are the antihyperlipidemic drug belonging to HMG-CoA reductase inhibitor and helps to reduce harmful cholesterol levels in blood. A rapid, specific and economic $U V$ spectrophotometric method has been developed using Methanol and distilled water in the ratio of (40:60) as a solvent for simultaneous determination of Simvastatin and Ezetimibe content in bulk and pharmaceutical dosage formulations. The absorbance values at $246 \mathrm{~nm}$ and $229 \mathrm{~nm}$ were used for the estimation of Ezetimibe and Simvastatin. The absorption maxima of Ezetimibe and simvastatin shown at $246 \mathrm{~nm}$ and $229 \mathrm{~nm}$ and methanol and distilled water in the ratio of (40:60) was used as solvent. This method obeyed Beer's law in the concentration range of 3-18 $\mathrm{\mu g} / \mathrm{ml}$ for simvastatin and 5-30 $\mathrm{gg} / \mathrm{ml}$ for Ezetimibe. The Simultaneous Estimation method was developed and validated according to ICH guidelines for linearity, precision, accuracy, LOD and LOQ. Simvastatin found to be linear within concentration range of $3-18 \mu \mathrm{g} / \mathrm{ml}$ with regression coefficient of 0.998 and Ezitimibe found to be linear within concentration range of $5-30 \mu \mathrm{g} / \mathrm{ml}$ with regression coefficient of 0.999 . The percentage $R S D$ value for the SMV at the concentration of 3, 6 and $9 \mu \mathrm{g} / \mathrm{ml}$ and their average \% RSD value were 0.350, 0.168 and 0.286 while for the EZT the concentration of 5,10 and $15 \mu \mathrm{g} / \mathrm{ml}$ and their average \% RSD value were $0.387,0.170$ and 0.282 . The average \% recoveries for three different concentrations was found to be $95.50 \%$ for SMV and $96.60 \%$ for EZT. The limit of detection and limit of quantification were found to be $0.33 \mu \mathrm{g} / \mathrm{ml}$ and $1.33 \mu \mathrm{g} / \mathrm{ml}$ for Simvastatin and $1.007 \mu \mathrm{g} / \mathrm{ml}$ and $4.04 \mu \mathrm{g} / \mathrm{ml}$ for Ezitimibe respectively by proposed $U V$ spectrophotometric method. The results of validation parameters indicates that the developed method was also found to be accurate, precise and sensitive and such simple \& economic method can be used for the simultaneous estimation of Simvastatin and Ezitimibe. The obtained results proved that the method can be employed for the routine analysis of simvastatin and Ezetimibe in bulks as well as in the commercial formulation.
\end{abstract}

Keywords: Simvastatin, Ezetimibe, Methanol, Distilled water, Simultaneous Estimation, UV spectrophotometry, ICH guidelines.

\section{INTRODUCTION}

Most of the pharmaceutical industries, are manufacturing multiple drug formulation to meet the market demand. It is a well-known fact that a combination of drug has a wider range to treat ailment as compared to a single drug components. There are many method reported for simultaneous analysis of drug component of multiple component formulation. Almost all pharmacopoeial methods available for the analysis of such formulation are applicable only after prior separation of drug components. Hence making them tedious and time consuming. There is likely to be loss of accuracy and precision 


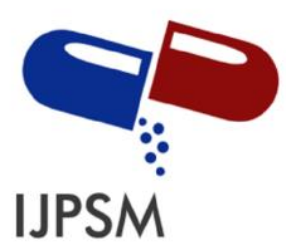

Birla Hariom et al, Int. Journal of Pharmaceutical Sciences and Medicine (IJPSM),

Vol.6 Issue. 1, January- 2021, pg. 40-50

ISSN: 2519-9889

Impact Factor: 3.426

due to extraction or separation. In the pharmaceutical field, for assurance of the quality of drug formulation, it become necessary to develop analytical method which should have accuracy and precision. The accuracy and precision depend upon the relative and absolute errors. Errors will be less, if the method is simple. The method can be directly related to accuracy and precision. Therefore simplicity of method should be one of the prime consideration while developing the method of analysis. The instrument technique that can be utilize for analysis is UV-Visible spectrometry ${ }^{1,2}$.

Simvastatin (SMV) and Ezitimibe (EZT) are the antihyperlipidemic drug belonging to HMG-CoA reductase inhibitor and helps to reduce harmful cholesterol levels in blood ${ }^{3}$.

The main objective of the study is to develop a rapid, specific and economic UV spectrophotometric method by using Methanol and distilled water in the ratio of (40:60) as a solvent for simultaneous determination of Simvastatin and Ezetimibe content in bulk and pharmaceutical dosage formulations ${ }^{4}$.

\section{MATERIALS AND METHOD}

\section{MATERIALS}

The drug samples, ezetimibe and simvastatin working standards were obtained as gift sample by Lupin Pvt. Ltd, Indore (MP) India. Starstat EZ $10 \mathrm{mg}$ marketed tablets manufactured by Lupin pvt. Ltd. and Simvotin $10 \mathrm{mg}$ manufactured by sun pharmaceutical limited was procured from local market. Methanol, and water used were analytical grade and were purchased from Merck Specialties Private Limited, Mumbai, India.

\section{INSTRUMENTATION:}

Variable wavelength programmable UV detector UV1800 double beam UV-Visible spectrophotometer was used to carry out spectral analysis and the data was recorded by Hitachi software. Sonicator (1.5L), Ultrasonicator was used to sonicating the mobile phase and samples. Standard and sample drugs were weighed by using Denver electronic chemical balance (SI-234) and $\mathrm{pH}$ of the mobile phase was adjusted by using Systronics digital $\mathrm{pH}$ meter. 


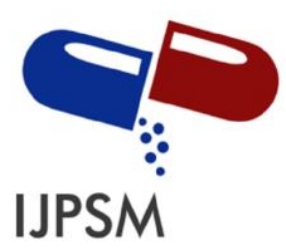

Birla Hariom et al, Int. Journal of Pharmaceutical Sciences and Medicine (IJPSM),

Vol.6 Issue. 1, January- 2021, pg. 40-50

ISSN: 2519-9889

III. EXPERIEMENTALS

Impact Factor: 3.426

\subsection{PREPARATION OF STANDARED STOCK SOLUTION:}

\section{A. Standard Simvastatine stock solution $(100 \mu \mathrm{g} / \mathrm{mL})$}

Simvastatine standard stock solution was prepared by weighing $10 \mathrm{mg}$ of Simvastatine and transferred to a $100 \mathrm{ml}$ volumetric flask and volume was made up to $100 \mathrm{ml}$ with Methanol \& Water in the ratio of 40: 60 (Methanol: Water) to get a concentration of $100 \mu \mathrm{g} / \mathrm{ml}$, The prepared solution is sonicated for 5 minutes and filtered through the whatman filter ${ }^{5}$.

\section{B. Standard Ezetimibe stock solution $(100 \mu \mathrm{g} / \mathrm{mL})$}

Ezetimibe standard solution was prepared by weighing $10 \mathrm{mg}$ of EZT to a ten ml volumetric flask and volume was made up to $100 \mathrm{ml}$ with with Methanol \& Water in the ratio of 40: 60(Methanol: Water) to urge a degree of $100 \mu \mathrm{g} / \mathrm{ml}$. The prepared solution is sonicated for 5 minutes and filtered through the whatman filter paper 5 .

\section{Sample drug stock solution $(100 \mu \mathrm{g} / \mathrm{mL})$}

The sample drug solution was prepared by weighing $10 \mathrm{mg}$ of powdred drug sample to a ten $\mathrm{ml}$ volumetric flask and volume was made up to $100 \mathrm{ml}$ with with Methanol \& Water in the ratio of 40: 60(Methanol: Water) to urge a degree of $100 \mu \mathrm{g} / \mathrm{ml}$. The prepared solution is sonicated for 5 minutes and filtered through the whatman filter paper ${ }^{5}$.

\subsection{DETECTION OF WAVELENGTH}

The spectrum of diluted solutions of the ezetimibe and simvastatin in methanol was recorded using Shimadzu Spectrophotometer UV-1800 (Shimadzu Corp. Japan). The peak of Ezitimibe and Simvastatin was obtained at $246 \mathrm{~nm}$ and $229 \mathrm{~nm}$. Which shows that drug is pure as given in the refrence $^{6}$. The UV spectrum of Ezitimibe and Simvastatin are shown in the fig. 1 and 2. 


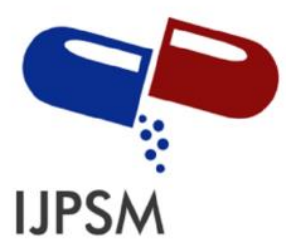

Birla Hariom et al, Int. Journal of Pharmaceutical Sciences and Medicine (IJPSM),

Vol.6 Issue. 1, January- 2021, pg. 40-50

ISSN: 2519-9889

Impact Factor: 3.426

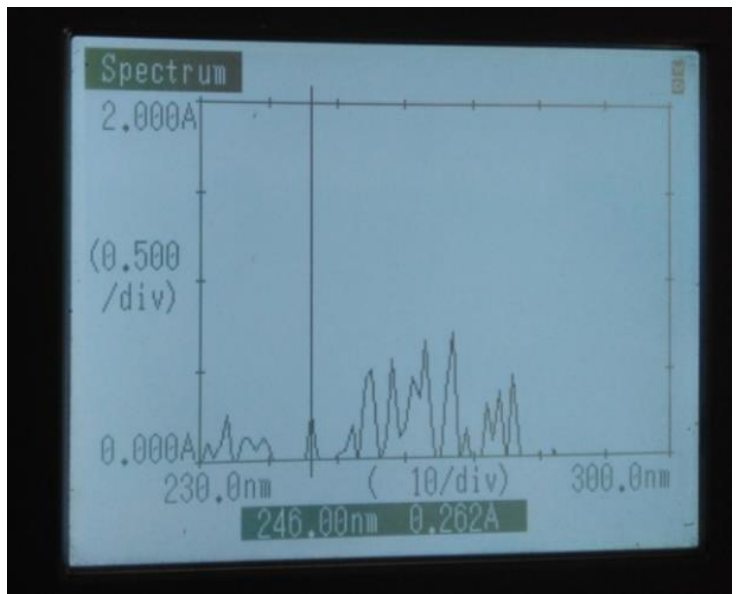

Fig.1. UV Spectra of Ezitimibe

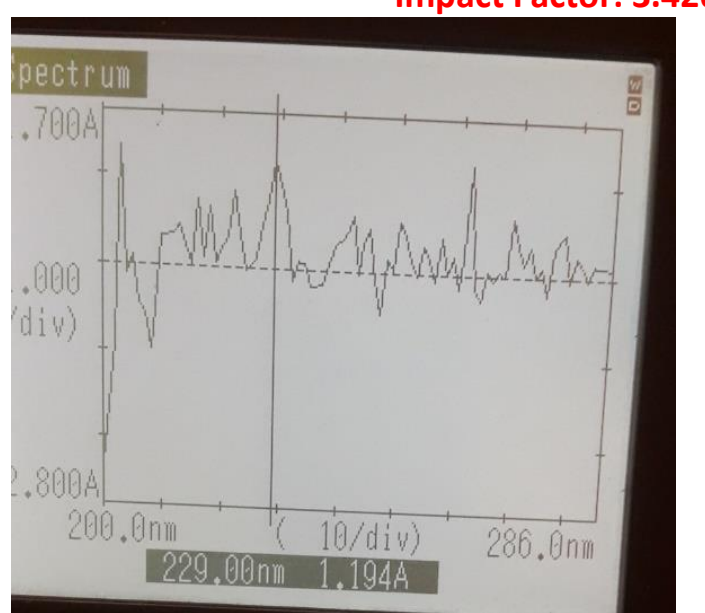

Fig.2. UV Spectra of Simvastatin

\subsection{CALIBRATION CURVE}

Calibration curve of Ezitimibe and Simvastatin was prepared in concentration range of 3-18 $\mu \mathrm{g} / \mathrm{mL}$ Simvastatine 5-30 $\mu \mathrm{g} / \mathrm{ml}$ Ezetimibe with Methanol and Water in the proportion of 40:60 ${ }^{7}$. The absorbance of each solution was measured at the wavelengths $246 \mathrm{~nm}$ and $229 \mathrm{~nm}$. The absorbance values (mean of five determinations) with their standard deviation at different concentration in the range of $5-30 \mu \mathrm{g} / \mathrm{ml}$ and $3-18 \mu \mathrm{g} / \mathrm{ml}$ are shown in the fig. 3 and 4 .

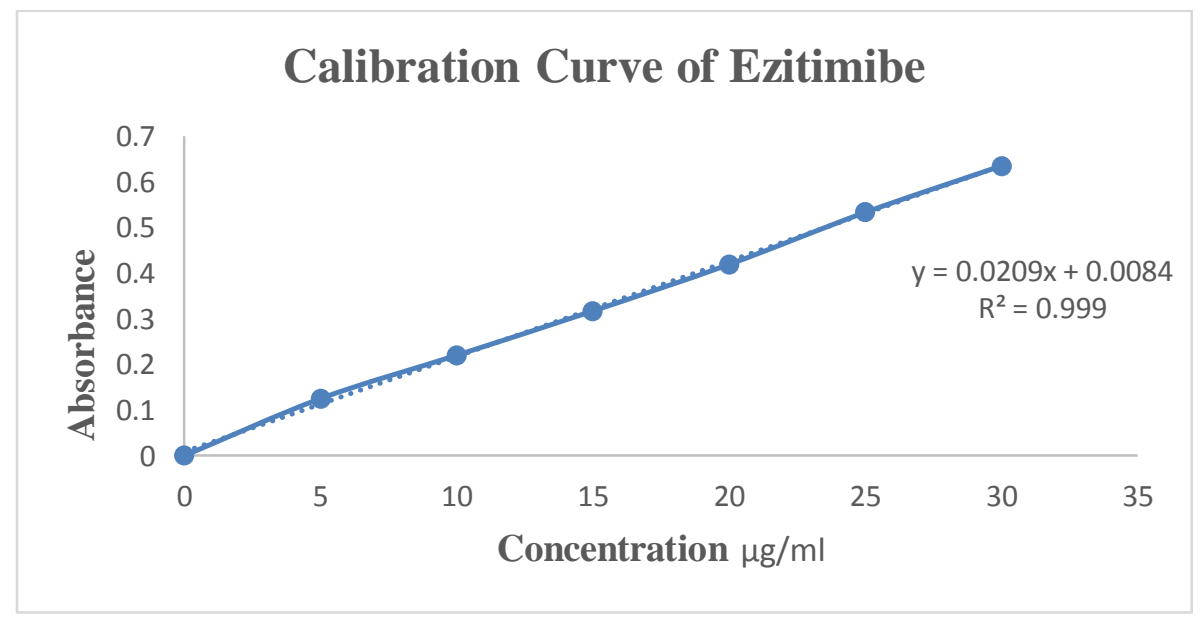

Fig. 3. Calibration Curve of Ezitimibe 


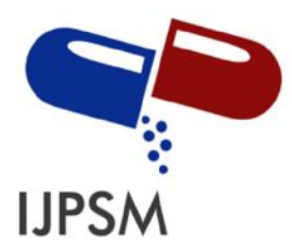

Birla Hariom et al, Int. Journal of Pharmaceutical Sciences and Medicine (IJPSM),

Vol.6 Issue. 1, January- 2021, pg. 40-50

ISSN: 2519-9889

Impact Factor: 3.426

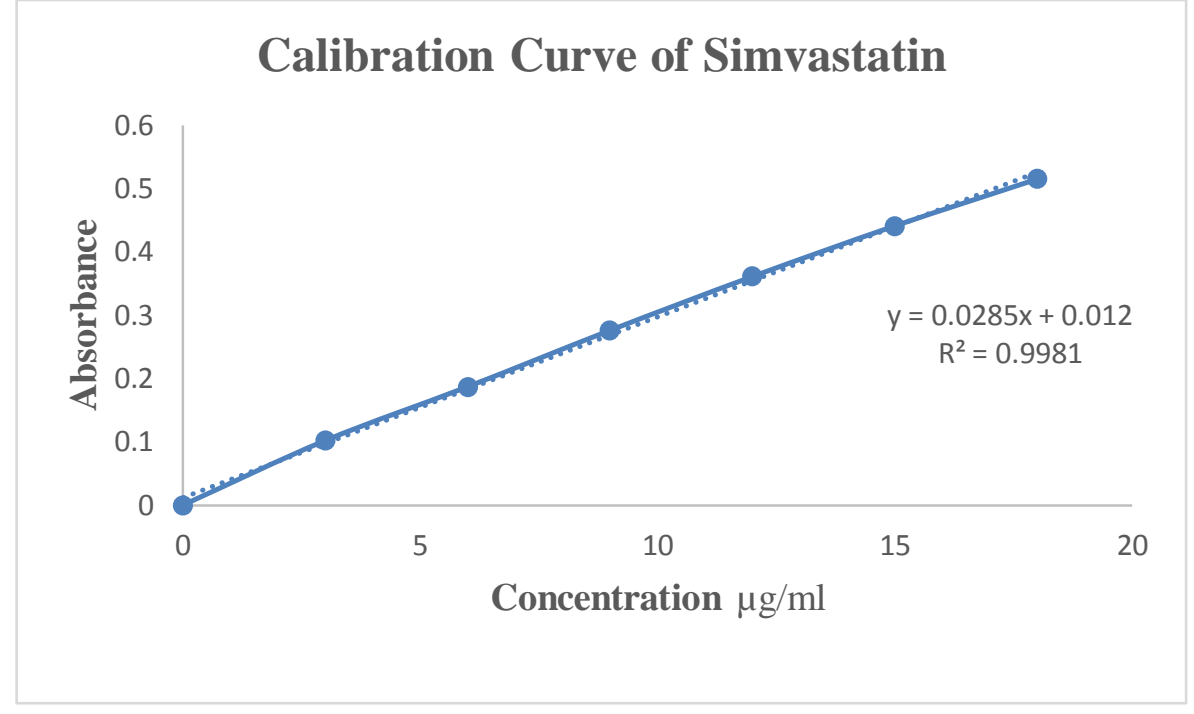

Fig.4. Calibration Curve of Simvastatin

\section{METHOD DEVELOPEMENT SIMULTANEOUS ESTIMATION METHOD}

The spectra of Ezetimibe and Simvastatine was used and wavelength 246 and $229 \mathrm{~nm}$ ( $\lambda$ max of EZT and $\lambda \max$ of SMV) were selected for the formation of the simultaneous equations. For calibration curves, stock solutions of Simvastatine and Ezetimibe within the concentration of range of $3-18$ $\mu \mathrm{g} / \mathrm{ml}$ and $5-30 \mu \mathrm{g} / \mathrm{ml}$ respectively. The absorbance of Simvastatine and Ezetimibe were measured at 229 and $246 \mathrm{~nm}$, calibration curves were plotted. The absoptivities of both the drugs at both the wavelengths were determined.

The absorbance and the absorptivity values at the particular wavelength were calculated and substituted in the following equation, to obtain the concentration ${ }^{8}$.

$\mathrm{CSIM}=(\mathrm{A} 1 \mathrm{ax} 2-\mathrm{A} 2 \mathrm{ax} 1) /(\operatorname{ax} 2 \mathrm{ay} 1-\mathrm{ax} 1 \mathrm{ay} 2) . \mathrm{CEZB}=(\mathrm{A} 2 \mathrm{ay} 1-\mathrm{A} 1 \mathrm{ay} 2) /(\mathrm{ax} 2 \mathrm{ay} 1-\mathrm{ax} 1 \mathrm{ay} 2)$.

Where, CSIM = Concentration of Simvastatine CEZB = Concentration of Ezetimibe respectively, A $1=$ absorbance of sample at $248 \mathrm{~nm}$, A $2=$ absorbance of sample at $229 \mathrm{~nm}$, 


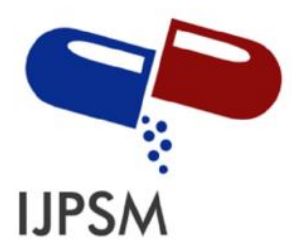

Birla Hariom et al, Int. Journal of Pharmaceutical Sciences and Medicine (IJPSM),

Vol.6 Issue. 1, January- 2021, pg. 40-50

ISSN: 2519-9889

Impact Factor: 3.426

ax1 = absorptivity of Simvastatine at $229 \mathrm{~nm}$ and ax2 $=$ absorptivityof Simvastatine at $246 \mathrm{~nm}$, ay1= absorptivity of Ezetimibe at $229 \mathrm{~nm}$ and ay $2=$ absorptivity of ezitimibe at $246 \mathrm{~nm}$.

At $\lambda 246 \mathrm{~nm}: 1.9=0.19 \mathrm{Cx}+0.19 \mathrm{Cy}$

At $\lambda 229 \mathrm{~nm}: 1.5=0.18 \mathrm{Cx}+0.12 \mathrm{Cy}$.

\section{VALIDATION}

Validation of the developed method was done according to the USP 2006, Asian edition.

\subsection{LINEARITY}

The linearity of the method is its ability to elicit test results that are directly proportional to the concentration of the analyte in samples. The calibration curve was taken in the range of $3-18 \mu \mathrm{g} / \mathrm{ml}$ for Simvastatine and 5-30 $\mu \mathrm{g} / \mathrm{mL}$ for Ezetimibe at the respective $\lambda \max ^{9}$. The correlation coefficient of the linearity was found to be 0.999 at each wavelength for both drugs as shown in table 1.

Table 1: Regression analysis of calibration graphs of Simvastatin and Ezitimibe for proposed UV Spectrophotometric method

\begin{tabular}{|l|l|l|l|}
\hline $\begin{array}{l}\text { Sr. } \\
\text { No. }\end{array}$ & Parameters & Results ( Simvastatin) & Results(Ezitimibe) \\
\hline 1. & Absorption maxima & $229 \mathrm{~nm}$ & $246 \mathrm{~nm}$ \\
\hline 2. & Beer's range & $3-18 \mu \mathrm{g} / \mathrm{ml}$ & $5-30 \mu \mathrm{g} / \mathrm{ml}$ \\
\hline 3. & Regression equation & $\mathrm{y}=0.0285 \mathrm{x}+0.012$ & $\mathrm{y}=0.0209 \mathrm{x}+0.0084$ \\
\hline 4. & Correlation coefficient & 0.9981 & 0.999 \\
\hline 5. & Slope & 0.0283 & 0.0211 \\
\hline 6. & Intercept & 0.012 & 0.0084 \\
\hline
\end{tabular}




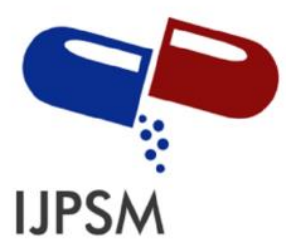

Birla Hariom et al, Int. Journal of Pharmaceutical Sciences and Medicine (IJPSM),

Vol.6 Issue. 1, January- 2021, pg. 40-50

ISSN: 2519-9889

Impact Factor: 3.426

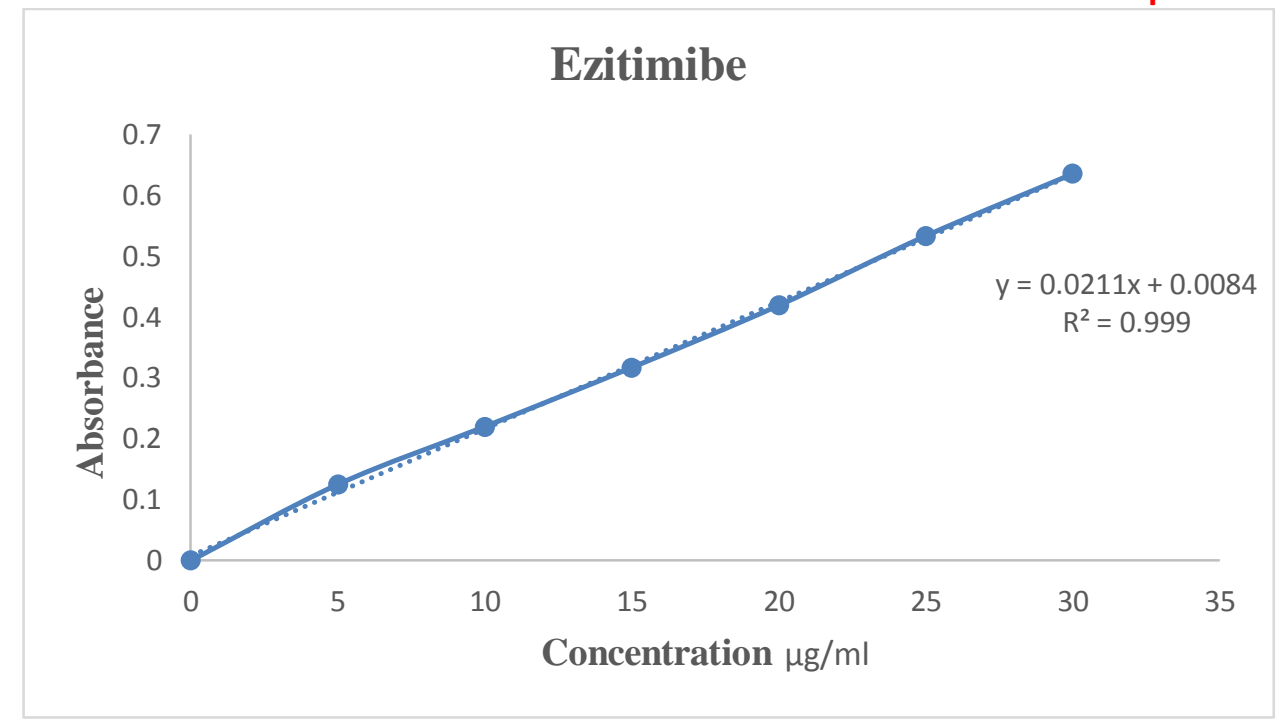

Fig. 5. Regression (Linearity) analysis for Ezitimibe

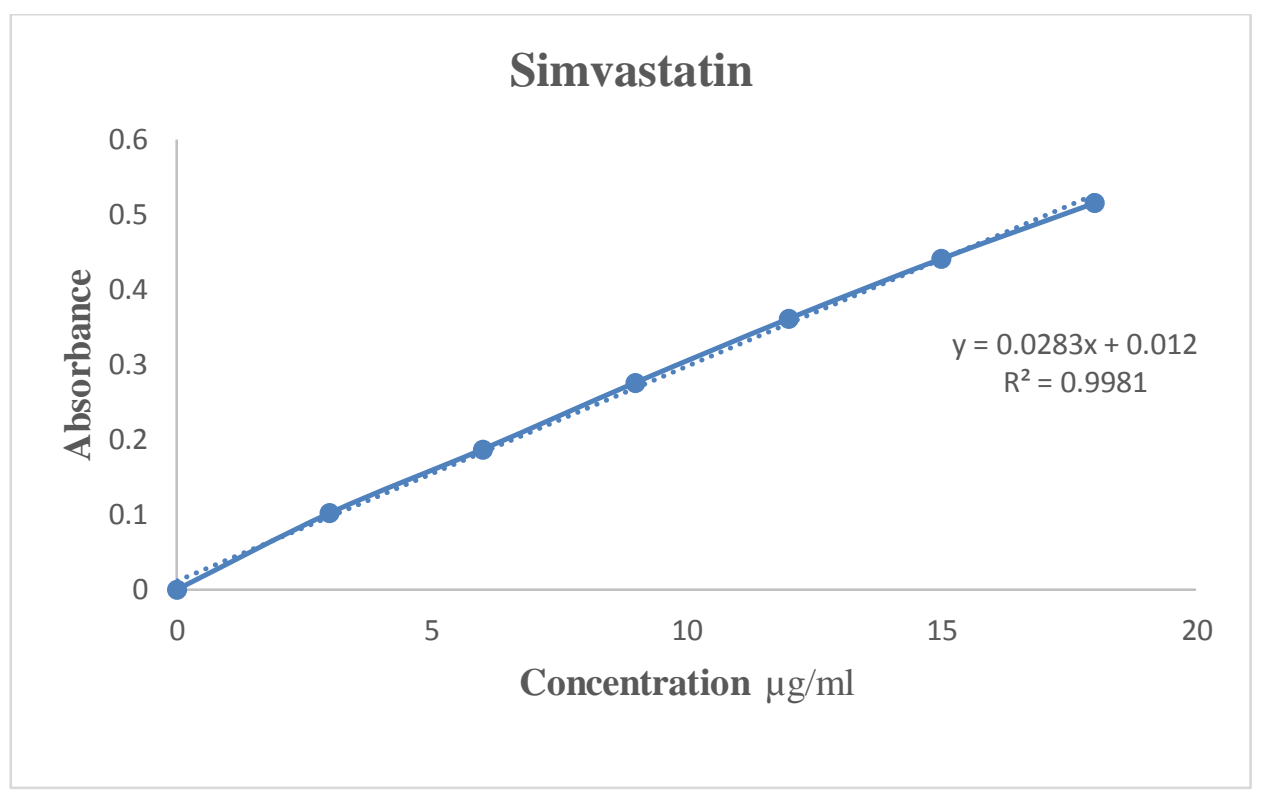

Fig. 6. Regression (Linearity) analysis for simvastatin

\subsection{ACCURACY}

In order to make sure the reliability and suitability of the proposed method, recovery studies were administered. It was done by mixing known quantity of ordinary drug with formulation sample and therefore the content were reanalysed by the proposed method. To a quantity of formulation like 10 mg of Simvastatin and Ezetimibe were added at 80\%, 100\% and 120\% levels. This was extracted 


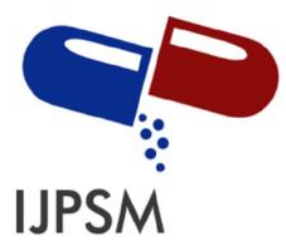

Birla Hariom et al, Int. Journal of Pharmaceutical Sciences and Medicine (IJPSM),

Vol.6 Issue. 1, January- 2021, pg. 40-50

ISSN: 2519-9889

Impact Factor: 3.426

diluted and reanalysed as per the formulation procedure. Absorbance were noted at respective wavelength ${ }^{10}$. Recovery studies were repeated for six times and the results are shown in table 2.

Table 2. Recovery (Accuracy) analysis for Simvastatin and Ezitimibe

\begin{tabular}{|l|l|l|l|l|l|l|l|}
\hline S.no & $\begin{array}{l}\text { Recovery } \\
\text { Level }\end{array}$ & \% Recovery & S.D \% & \% RSD & \% Recovery & S.D \% & \% RSD \\
\hline & \multicolumn{3}{|c|}{ Simvastatine } & & \multicolumn{3}{c|}{ Ezetimibe } \\
\hline 1. & $80 \%$ & 95.50 & 0.05670 & 0.2872 & 96.60 & 0.02732 & 0.2793 \\
\hline 2. & $100 \%$ & 94.20 & 0.0258 & 0.3120 & 95.66 & 0.0429 & 0.5145 \\
\hline 3. & $120 \%$ & 94.36 & 0.03240 & 0.70590 & 96.36 & 0.05123 & 0.6176 \\
\hline
\end{tabular}

\subsection{PRECISION}

The precision of an analytical method is decided by assaying a sufficient number of aliquots of a homogeneous sample to be ready to calculate statistically valid estimate of twenty-two Relative Standard Deviation (\%RSD). Intermediate precision was done to precise within laboratory variation, on different days. Five replicates of $8 \mu \mathrm{g} / \mathrm{mL}$ concentration of the working standard mixture and sample solution were analysed \%RSD was found to be less than $2 \%{ }^{11}$. The results are shown in table 3.

Table 3. Result of Intraday (Repeatability) Precision studies

\begin{tabular}{|l|l|l|l|l|l|l|l|}
\hline S.no & Parameters & \multicolumn{3}{|c|}{$\begin{array}{c}\text { \% Amt. found } \\
\text { ( Simvastatin) }\end{array}$} & \multicolumn{3}{c|}{$\begin{array}{c}\text { \% Amt. found } \\
\text { (Ezitimibe) }\end{array}$} \\
\hline & & $3 \mu \mathrm{g} / \mathrm{ml}$ & $6 \mu \mathrm{g} / \mathrm{ml}$ & $9 \mu \mathrm{g} / \mathrm{ml}$ & $5 \mu \mathrm{g} / \mathrm{ml}$ & $10 \mu \mathrm{g} / \mathrm{ml}$ & $15 \mu \mathrm{g} / \mathrm{ml}$ \\
& & & & & & & \\
\hline 1. & Morning & 99.89 & 99.65 & 99.48 & 99.93 & 99.56 & 99.35 \\
\hline 2. & Afternoon & 99.69 & 99.69 & 100.05 & 99.66 & 99.97 & 99.98 \\
\hline 3. & Evening & 99.21 & 99.21 & 99.72 & 99.28 & 99.22 & 99.78 \\
\hline 4. & Mean & 99.59 & 99.79 & 99.75 & 99.48 & 99.84 & 99.76 \\
\hline 5. & S.D. & 0.349 & 0.168 & 0.286 & 0.385 & 0.170 & 0.282 \\
\hline 6. & \% R.S.D. & 0.350 & 0.168 & 0.286 & 0.387 & 0.170 & 0.282 \\
\hline
\end{tabular}




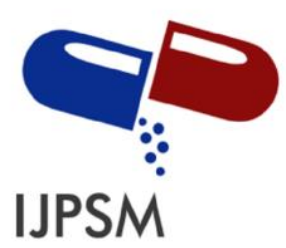

Birla Hariom et al, Int. Journal of Pharmaceutical Sciences and Medicine (IJPSM),

Vol.6 Issue. 1, January- 2021, pg. 40-50

ISSN: 2519-9889

Impact Factor: 3.426

\subsection{LIMIT OF DETECTION AND LIMIT OF QUANTIFICATION}

It is the lowest amount of analyte and lowest concentration of analyte in a sample that can be detected but not necessarily quantitated under the stated experimental conditions. Limit of detection can be calculated using following equation as per ICH guidelines ${ }^{12}$. The results are shown in table 4 .

$\mathrm{LOD}=3.3 \times \mathrm{N} / \mathrm{S}$ Where,

$\mathrm{N}=$ Standard deviation of the responce and $\mathrm{S}=$ Slope of the corresponding calibration curve

The limit of detection and limit of quantification were found to be $0.33 \mu \mathrm{g} / \mathrm{ml}$ and $1.33 \mu \mathrm{g} / \mathrm{ml}$ for Simvastatin and $1.007 \mu \mathrm{g} / \mathrm{ml}$ and $4.04 \mu \mathrm{g} / \mathrm{ml}$ for Ezitimibe respectively by proposed UV spectrophotometric method. Results of LOD and LOQ are summarized in (Table 4).

Table 4. Limit of detection (LOD) and limit of quantification (LOQ) of Simvastatin and Ezitimibe

\begin{tabular}{|l|l|l|l|}
\hline S.no & Parameters & \multicolumn{2}{|l|}{ Method(Simultaneous estimation method) } \\
\hline & & Simvastatine & Ezetimibe \\
\hline 1. & LOD $(\mu \mathrm{g} / \mathrm{ml})$ & 0.33068 & 1.3360 \\
\hline 2. & LOQ $(\mu \mathrm{g} / \mathrm{ml})$ & 1.0073 & 4.0485 \\
\hline
\end{tabular}

\section{ACKNOWLEDGEMENT}

I am thankful to the management of Swami Vivekanand College of pharmacy Indore. For providing necessary facilities to carry out the research work and heartily thankful to my guide Ms. Archana Dubey for providing all the support and encouragement to carry out this studies.

\section{CONCLUSION}

It can be concluded that the Simultaneous estimation and Method development for both the drugs was performed and it gave good results. The best result was given by methanol solvent. 


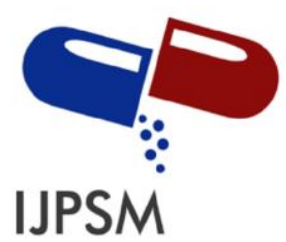

Birla Hariom et al, Int. Journal of Pharmaceutical Sciences and Medicine (IJPSM),

Vol.6 Issue. 1, January- 2021, pg. 40-50

ISSN: 2519-9889

Impact Factor: 3.426

As method development procedure, validation studies were also performed for the same, but due to limited quantity of the compound only few parameters were observed as Linearity, limit of detection, Limit of quantification, Precision and linearity.

The validation procedure followed were as per the ICH guidelines. Simvastatin and Ezitimibe both gave excellent results. Since there were no reference results for this study, so the results were not compared to any standard.

The linearity was achieved with methanol solvent, Linearity, Accuracy and precision were satisfactory and the limit of detection (LOD), limit of quantitation achieved was also satisfactory. Hence we conclude that the simple, rapid, less-time consuming, cost effective and precise method was developed and validated by UV-spectroscopy with the simultaneous estimation of simvastatin and ezitimibe.

\section{REFERENCES}

[1]. Blanco $m$ and alcala m. European j. Pharma. Sci. 2006; 27(2-3): 280.

[2]. Mcdowell ae, horner rs and pardue hl. Clin.chem.1976; 22:1862.

[3]. Sethi Pd. In; quantitative analysis of drugs in pharmaceutical formulations. Unique publishers, delhi.1999: 51.

[4]. Praveen kumar, yusra Ahmad, amitav ghosh, a stability indicating rphplc method development for determination of ezetimibe in tablet dosage form, der pharma chemica, 2012, 4 (3):1296-1304.

[5]. Varsha balkrishna mane*, surekha Babar, nita kulkarni. Development of UV spectrophotometric method for the simultaneous estimation of simvastatine and ezetimibe in tablet dosage form by simultaneous equation and absorbance ratio method. International journal of pharmtech research vol.3, no.3, pp 1459-1466, july-sept 2011.

[6]. Vinit chavhan and minal ghante stability indicating uv spectrophotometric method development and validation of simvastatin in bulk and tablet dosage form $\mathrm{j}$ app pharm vol. 6; issue 2: 235 -246; april, 2014.

[7]. Varsha balkrishna mane*, surekha Babar, nita kulkarni. Development of UV spectrophotometric method for the simultaneous estimation of simvastatine and ezetimibe in tablet dosage form by simultaneous equation and absorbance ratio method. International journal of pharmtech research vol.3, no.3, pp 1459-1466, july-sept 2011.

[8]. metreyi sharma, deepali v. Mhaske, m. Mahadik, s. S. Kadam, and s. R. Dhaneshwar uv and three derivative spectrophotometric methods for determination of ezetimibe in tablet formulation indian $\mathrm{j}$ pharm sci. 2008 mar-apr; 70(2): 258-260.

[9]. Vinit chavhan and minal ghante stability indicating uv spectrophotometric method development and validation of simvastatin in bulk and tablet dosage form $\mathrm{j}$ app pharm vol. 6; issue 2: 235 -246; april, 2014.

[10].Varsha balkrishna mane, surekha Babar, nita kulkarni. Development of UV spectrophotometric method for the simultaneous estimation of simvastatine and ezetimibe in tablet dosage form by simultaneous 


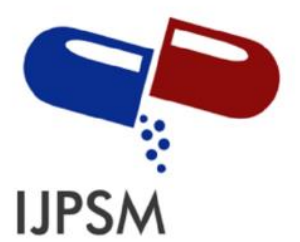

Birla Hariom et al, Int. Journal of Pharmaceutical Sciences and Medicine (IJPSM),

Vol.6 Issue. 1, January- 2021, pg. 40-50

ISSN: 2519-9889

Impact Factor: 3.426

equation and absorbance ratio method. International journal of pharmtech research vol.3, no.3, pp 1459-1466, july-sept 2011.

[11].S. J. Rajput and h. A. Raj simultaneous spectroscopic estimation of ezetimibe and simvastatin in tablet dosage forms indian j pharm sci, 2007, 69 (6): 759-762.

[12]. Ramakrishna k, pani kumar ad, venkat raju y, sunitha g, rebecca shiffali d, bhandhavi s, development of validated rp-hplc method for the estimation of ezetimibe in bulk drug and formulations, rjpbcs, january - march, 2011, volume 2 issue 1. 